\title{
Work Week, Vacations, and Salaries in Medium-Sized Universities and Colleges
}

\author{
Dr. Muller is director of libraries, South- \\ ern Illinois University.
}

SAlaries for professional librarians are $\mathcal{S}$ generally reported in terms of annual amounts. If comparison of salaries of different institutions are made, however, it may be desirable to know more than the annual amounts. Specifically, we may wish to take into account such factors as the number of hours of work per year, the nuinber of legal holidays with pay, the number of days of sick leave allowed, the amount contributed by the institution towards retirement plans and insurance, and sabbatical or similar leave policies applicable to the library staff.

The present analysis is confined to the factor of inter-institutional variations in the number of hours of work per work year, without considering other factors that may contribute to the attractiveness of library positions. In a questionnaire addressed to 56 medium-sized institutions of higher education, of which 42 had reported salary data in the January, 1953 issue of $C \xi R L$, we asked two questions: I. How long are the annual vacations with pay which members of your professional library staff receive, including all school recesses if librarians are not required to work during them, but omitting individual legal holidays? 2. How long is the work week of professional library staff members, exclusive of officially permitted regular rest periods? -Replies were received from 49 libraries ${ }^{1}$ in April, 1953, of which 39 had reported salary data in $C छ R L$.

\section{VACATIONS}

The modal practice was to allow 4 weeks vacation a year: 29 out of 49 institutions followed this practice. Sixteen institutions allowed between 5 and 8 weeks vacation a year, and 4 institutions provided only 3 weeks a year. In a few cases, the length of vacation varied according to the number of years that an employee had wirked for the institution.

\section{WORK WEEK}

As to the length of the work week, the modal practice was 40 hours a week, with I 8 of the 49 libraries reporting such a work week; only one institution reported a work week of over 40 hours (44). At one institution, the number of hours was not offcially specified but worked out to about 40 . Over one-half of the libraries required 39 hours a week or less, the minimum being 35 hours a week. Three institutions also followed the practice of lowering the number of work hours per week during the

\footnotetext{
${ }^{1}$ The following institutions, listed in the order of enrollment from low to high, returned answers: Vassar, Wellesley, U. of North Dakota, Montana State, Tufts, So. Illinois U., Dartmouth, U. of S. Carolina, U. of Vermont, U. of Maine, Virginia Poly. Inst., Emory U., Ut of Rochester, U. of New Hampshire, Brown U. New Mexico, Howard U., U. of W. Virginia, U. of Georgia U. of Oregon,' So. Methodist U., Oregon State, Notre Dame U., 'U. of Arizona U. of Louisville, Uotre Dame of Kentucky, San Francisco Stat of Louisville, . of Kentucky, San Francisco State Teachers, U. of Kansas, Texas A\&M, U. of Colorado, U. of Utah, U. of Tennessee, Hunter, U. of Oklahoma, Purdue U., Iowa State, Syracuse U., U. of Denver, U. of Buffalo, Brooklyn College, St. Louis U., U. of Houston, Washington U. (St. Louis), U. of Maryland, Michigan State, U, of Cincinnati.
} 
TABLE I

Length of Work Week and Vacations

\begin{tabular}{|c|c|c|c|c|c|c|c|c|}
\hline \multirow{2}{*}{$\begin{array}{l}\text { Number of Weeks of } \\
\text { Vacation Annually }\end{array}$} & \multicolumn{8}{|c|}{ Number of Hours of Work Per Week } \\
\hline & . 35 & 36 & 37 & 38 & 39 & 40 & 44 & Total \\
\hline $\begin{array}{l}3 \\
4 \\
5 \\
6 \\
7 \\
8\end{array}$ & I & $\begin{array}{l}\text { I } \\
\text { I } \\
2 \\
\text { I }\end{array}$ & $\begin{array}{l}\text { I } \\
\text { I }\end{array}$ & $\begin{array}{l}7 \\
2 \\
\text { I }\end{array}$ & $\begin{array}{l}\text { I } \\
6 \\
\text { I } \\
2 \\
\text { I }\end{array}$ & $\begin{array}{c}\text { I } \\
\text { I } 4 \\
\text { I } \\
2\end{array}$ & $\mathbf{I}$ & $\begin{array}{r}4 \\
29 \\
3 \\
8 \\
2 \\
3\end{array}$ \\
\hline Total & I & 5 & 3 & IO & I I & I 8 & I & 49 \\
\hline
\end{tabular}

summer months to 34,32 , and 30 hours, respectively.

\section{HOURS PER YEAR}

Table I above shows the distribution of all the libraries with respect to number of weeks of vacation annually and number of hours of work per week. Practices were far from uniform.

The foregoing data on vacations and work weeks can also be presented in terms of total number of hours per year, as follows :

TABLE II

Length of Work Year in Hours

\begin{tabular}{ll}
\hline \hline Minimum & \\
25 th percentile & I, 552 \\
Median & , 794 \\
75 th percentile & , 872 \\
Maximum & I, 920 \\
& 2,156 \\
\hline
\end{tabular}

If all libraries followed a uniform practice of allowing 4 weeks of vacation a year, the middle 50 per cent of the libraries would provide a work week ranging from $37 \frac{1}{3}$ to 4 o hours, with a median of 39 hours.

\section{RELATION OF WORK YEAR TO SALARY}

To determine how differences in the work year affected reported rates of compensation, the minimum salaries for professional librarians, as reported, were equated by converting them into figures based on a uniform number of hours per year; the number selected for equating the salaries was the median for the 49 libraries, that is, 1872 hours. In 27 of the libraries the equated salaries were higher than the reported salaries by amounts up to $\$ 849$, the maximum increase amounting to 25 per cent of the reported salary; in 22 libraries, the equated salaries were lower by amounts up to $\$ 364$, the maximum decrease amounting to 15 per cent of the reported salary. Differences between reported and equated salaries were not sufficient, however, to affect the rank order of the salaries appreciably: the Spearman rank order coefficient of correlation between the series of reported and the series of equated salaries was +o.91.

How differences in the length of the work year and the length of the work week, considered together, influence equated salaries is illustrated in Table III.

In each of the four pairs, the reported salaries were approximately identical whereas the equated salaries were apart by $\$ 955$, $\$ 1029, \$ 468$, and $\$ 936$, respectively. Thus it appears that comparisons between reported salaries can be greatly misleading unless the length of the work year is taken into account. Salaries in libraries providing relatively long vacations and a short work week are not strictly comparable to salaries in libraries with less favorable working conditions. It may be argued that the indi- 
TABLE III

Selected Pairs of Reported Salaries Equated to a Common Base of 1872 Hours a Year (Minimum Salaries for Library Assistants, 1952-53)

\begin{tabular}{|c|c|c|c|c|}
\hline & $\begin{array}{l}\text { Reported } \\
\text { Salary }\end{array}$ & $\begin{array}{l}\text { No. of Hours } \\
\text { a Year }\end{array}$ & $\begin{array}{l}\text { Rate Per } \\
\text { Hour }\end{array}$ & $\begin{array}{c}\text { Salary Equated } \\
\text { to } 1872 \text { Hours } \\
\text { a Year }\end{array}$ \\
\hline $\begin{array}{l}\text { Brooklyn C. } \\
\text { Michigan State C. }\end{array}$ & $\begin{array}{r}\$ 3,700 \\
3,700 \\
\end{array}$ & $\begin{array}{l}I, 574 \\
I, 920\end{array}$ & $\begin{array}{l}2.35 \\
1.84\end{array}$ & $\begin{array}{r}\$ 4,399 \\
3,444 \\
\end{array}$ \\
\hline Difference & none & & & $\$ 955$ \\
\hline $\begin{array}{l}\text { Vassar C. } \\
\text { San Francisco State C. }\end{array}$ & $\begin{array}{r}\$ 3,400 \\
3,372\end{array}$ & $\begin{array}{l}\text { I , } 543 \\
\text { I } 960\end{array}$ & $\begin{array}{l}2.27 \\
1.72\end{array}$ & $\begin{array}{r}\$ 4,249 \\
3,220\end{array}$ \\
\hline Difference & $\overline{\$ 28}$ & & & $\overline{\$ 1,029}$ \\
\hline $\begin{array}{l}\text { Hunter C. } \\
\text { U. of New Hampshire }\end{array}$ & $\begin{array}{r}\$ 3,100 \\
3,100 \\
\end{array}$ & $\begin{array}{l}1,668 \\
1,920\end{array}$ & $\begin{array}{l}1.86 \\
1.61\end{array}$ & $\begin{array}{r}\$ 3,482 \\
3, \text { OI } 4 \\
\end{array}$ \\
\hline Difference & none & & & $\$ 468$ \\
\hline $\begin{array}{l}\text { Wellesley C. } \\
\text { Texas A\&M }\end{array}$ & $\begin{array}{r}\$ 2,800 \\
2,760 \\
\end{array}$ & $\begin{array}{l}1,575 \\
2,156\end{array}$ & $\begin{array}{l}\mathrm{I} .78 \\
\mathrm{I} .28\end{array}$ & $\begin{array}{r}\$ 3,332 \\
2,396 \\
\end{array}$ \\
\hline Difference & $\$ 40$ & & & $\$ 936$ \\
\hline
\end{tabular}

vidual professional library staff member is primarily interested in his total annual income rather than in the rate per hour. Nevertheless if there is a choice between two $\$ 3700-a-y e a r$ positions of which one requires 1920 hours of work a year and the other only 1574, most job seekers will not find it difficult to reach a decision, assuming that all other factors are about equal. Differences in the length of the work year between libraries may correspond to similar inter-institutional differences in faculty teaching loads. To what extent the length of the work year can be changed by authority of head librarians is not known; in many cases such matters are regulated by college authorities or statutes and are difficult to change. The question whether greater uniformity among libraries would be desirable may be worth considering. However, as long as fairly. wide variations prevail, it seems important that data on the length of the work week and vacations be reported in conjunction with published salary figures.

\section{Revision of The University Library}

The University Library, issued by the University of Chicago Press in 1945 and reprinted in 1948 , is in process of revision by the authors, Louis Round Wilson and Maurice F. Tauber. The authors would be grateful to librarians if they will send any suggestions for the revision to Dr. Wilson, University of North Carolina, or Dr. Tauber, School of Library Service, Columbia University. 